Article

\title{
Benchmark of the Trends of Spatial Inequality in World Megaregions
}

\author{
Ziqi Liu ${ }^{1}$, Ming Zhang ${ }^{1, *(1)}$ and Liwen Liu ${ }^{2}$ \\ 1 Community and Regional Planning, School of Architecture, University of Texas at Austin, \\ Austin, TX 78712, USA; zqliu212132@utexas.edu \\ 2 Department of Urban and Rural Planning, College of City Construction, Jiangxi Normal University, \\ Nanchang 330022, China; liuliwen305@163.com \\ * Correspondence: zhangm@austin.utexas.edu
}

check for updates

Citation: Liu, Z.; Zhang, M.; Liu, L. Benchmark of the Trends of Spatial Inequality in World Megaregions. Sustainability 2021, 13, 6456. https:// doi.org/10.3390/su13116456

Academic Editor: Gema

Fernández-Avilés

Received: 11 April 2021

Accepted: 3 June 2021

Published: 6 June 2021

Publisher's Note: MDPI stays neutral with regard to jurisdictional claims in published maps and institutional affiliations.

Copyright: (c) 2021 by the authors. Licensee MDPI, Basel, Switzerland. This article is an open access article distributed under the terms and conditions of the Creative Commons Attribution (CC BY) license (https:// creativecommons.org/licenses/by/ $4.0 /)$.

\begin{abstract}
There have been growing concerns around the world over the rising spatial inequality (SI) amid fast and vast globalization. This paper presents an effort to benchmark the conditions and trends of spatial inequality in 37 megaregions in the United States, Europe, and China. Furthermore, the study selected three megaregion examples and analyzed the effect of developing high-speed rail (HSR) as an infrastructure investment strategy on reshaping the spatial pattern of job accessibility. The study measures spatial inequality with the Theil index of gross regional product and with the rank-size coefficient of polycentricity. Results show that spatial inequality exists and varies in magnitude within and between megaregions. On average, Chinese megaregions exhibited the level of spatial inequality about two times or more of those in the U.S. and European megaregions. The decade between 2006 and 2016 saw a decrease in the Theil index measure of megaregional inequality in China, but a slight increase in the United States and Europe. Fast growing megaregions exhibit high levels and rising trends of spatial inequality regardless of the country or continent setting. HSR helps improve mobility and accessibility; yet the extent to which HSR reduces spatial inequality is context dependent. This study presents a first attempt to assess and compare the spatial inequality conditions and trajectories in world megaregions aiming at promoting international learning.
\end{abstract}

Keywords: spatial inequality (SI); megaregions; high-speed rail (HSR); The Texas Triangle; The Northern Powerhouse; The Mid-Yangtze River City Cluster

\section{Introduction}

The core interest of this paper is to assess spatial inequality (SI) and the role of major transportation investments, specifically high-speed or high-performance rail (HSR), in shaping SI of large-sized regions or megaregions. SI in general terms denotes the difference in spatially-defined attributes (for example, industrial specialization and household income), which may present as desired or undesired (un)even distributions over space [1]. This study focuses on the undesired spatial difference in a megaregional context. SI, therefore, in our study, refers to the development disparity or imbalance within and between megaregions. Reducing SI has been an ongoing effort for international organizations, national governments, and regional as well as local agencies [2-4]. The concern has been growing recently over the worsening inequality, spatial and nonspatial, amid the fast and vast globalization in the past decades. While globalization has contributed to economic growth and poverty reduction in many parts of the world, the gap is also widening between the fast-growing coastal zones and the hinterland in the emerging market economies, between the urbanized areas and rural communities, and between superstar cities and the left-behind places in the developed world [5,6]. Serious spatial inequality can lead to increased inequity, worsened environmental injustice, and rising social instability. The alarming trend of growing inequality between places and regions calls for updated research 
on the spatiality and the shaping forces of inequality as well as the effectiveness of various policy interventions to reduce it $[7,8]$.

Our focal interest in megaregional SI was motivated by the phenomenon of mega agglomeration, which is also engendered by globalization forces. A mega agglomeration is typically featured with multiple interconnected metropolitan areas along with their socially or ecologically integrated surroundings. The mega agglomeration phenomenon has attracted strong attentions from scholars, practitioners, and policy makers from around the world [9-12]. Studies from different countries or agencies have described the mega agglomeration phenomenon with different expressions. For instance, the U.S. scholars name the mega agglomeration as megaregion. In Europe and China, similar mega agglomerations are called Mega-City Regions and City-Cluster Regions, respectively. A new wave of research on SI has accumulated new empirical evidence and shed new lights on SI conditions and dimensions, factors contributing to SI, and policy alternatives to address SI concerns [13]. The majority of these studies, however, have examined SI focusing on the conventional geographies, e.g., cities or counties, metropolitan areas, states, or countries. Few looked at SI from a megaregional perspective despite strong policy and investment interests in megaregions.

Among many strategies taken to reduce SI, investing in major transportation infrastructure has been a common one [8]. It is expected that improved transportation infrastructure help elevate mobility and enhance access to opportunities and consequently promote balanced development between the constituents of regions and population. One notable example is the European Union's European Spatial Development Perspective (ESDP) [14]. ESDP aimed to improve territorial coherence and spatial integration. Investments in multimodal Trans-European Transportation Network (TEN-T) worked in line with ESDP objectives. HSR investments have become a frequently advocated strategy to balance megaregional development. For instance, China has been investing in a national HSR grid as part of a national spatial development plan to narrow the disparity between the West and the East region and between cities within a city-cluster region [15]. In the UK, the Northern Powerhouse initiative aimed to reduce the disparity between the North and the South of England through HSR and other infrastructure investments [16]. In the United States, advocates have recommended to invest in HSR or high-performance rail to regenerate the bypassed and underdeveloped communities. Nevertheless, there have been no studies to analyze the implications of investing HSR for reducing megaregional SI in a cross-continental setting.

The study presented in this paper sets a twofold objective. First, the study aims to benchmark the SI conditions and trends of megaregions in multiple continents. Second, the study explores the effects (revealed or potential) of major transportation investments in reshaping SI of megaregions. This study examines megaregional SI from three different contexts, the United States, Europe, and China. It is expected that the multi-continental SI studies will help facilitate international learning to improve the understanding of spatial inequality and to explore effective policy strategies for reducing disparity.

The rest of the paper includes four parts. Section 2 introduces the background of megaregion study and reviews related studies on SI. Section 3 presents study methods, describing the analysis approach, data sources, and SI indicators. Section 4 presents SI analysis results and findings. Finally, the paper ends with concluding remarks and discussions on future research.

\section{Background and Related Studies}

\subsection{Background on Megaregion Study}

Megaregions, or mega-city regions in Europe and city-cluster regions in China, can find their conceptual origin from megalopolis observed by French geographer Jean Gottman (1961) and World Cities analyzed by Peter Hall (1966) in the 1950s to 1960s. The renewed interest in megaregions beginning after the turn of the 21st century lies in the premise that, in the globalized economy, it is these mega-agglomerations, not individual cities, that play 
a key role for competition. The U.S. projections show that three fourths of U.S. jobs and population will concentrate in the eleven megaregions by 2050. While a number of scholars have come up with their own delineations of U.S. megaregions [17-20], they share the view of the urgent research needs to understand megaregional challenges and devise a megaregional approach to address issues in institutional/legal, analytical, environmental, and social dimensions. The U.S. Department of Transportation (DOT) published its strategic plan in 2016, "Beyond Traffic 2045: Trends and Choices", which highlights the significance of megaregions to the nation's future and calls for actions (Figure 1). From 2016-2018, the U.S. Federal Highway Administration organized nine megaregion workshops across the country to facilitate discussions on key issues surrounding megaregions such as economic vitality, environment/air quality, freight, infrastructure/congestion, and safety. Each event focused on issues specific to that megaregion, and included efforts to create dialogue regarding common transportation topics of mutual concern across jurisdictional boundaries.

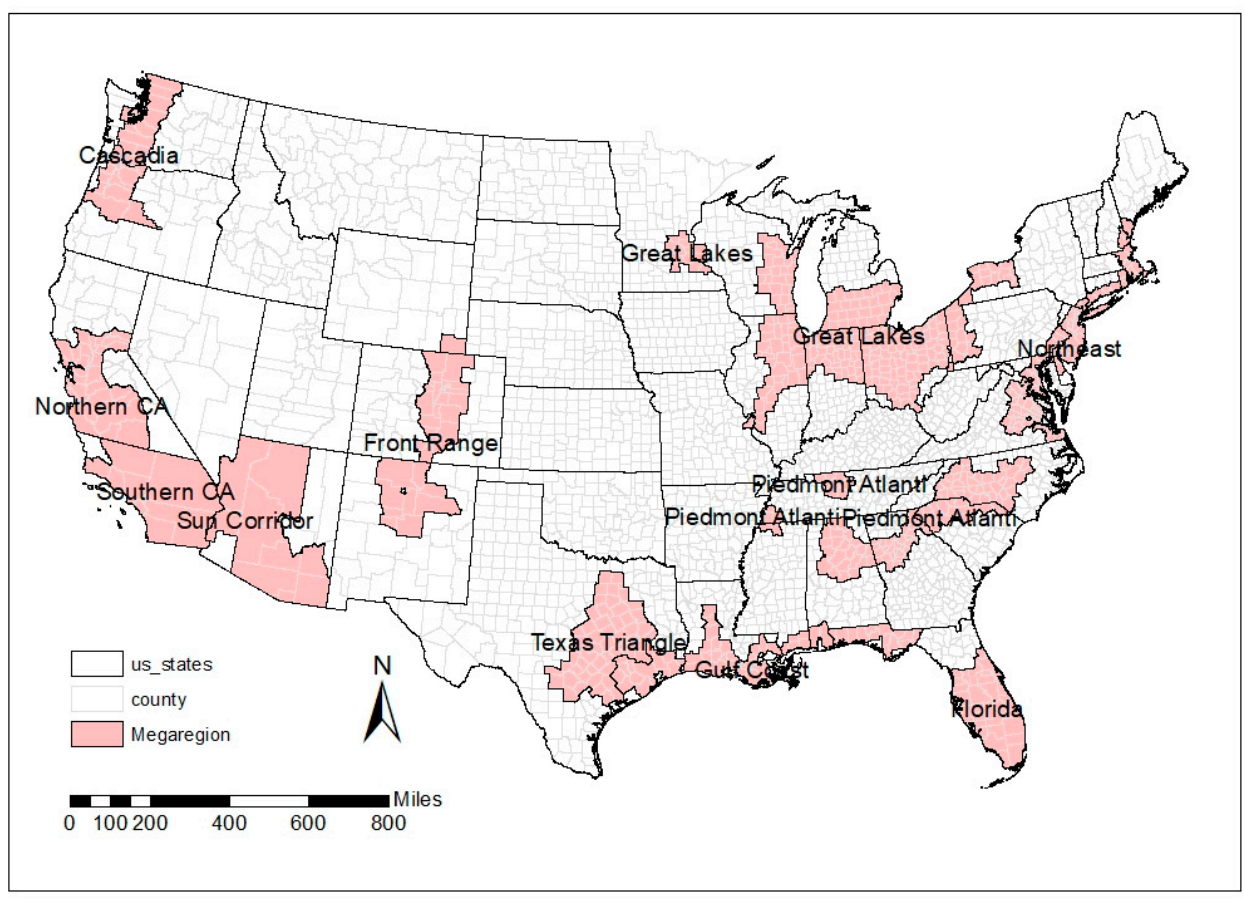

Figure 1. Eleven Megaregions in the United States.

The Polynet project represents a recent collective effort to study mega agglomerations in Europe. Polynet was led by Peter Hall and Kathy Pain (2006) with networked researchers from the UK, Belgium, France, Ireland, the Netherlands, and Switzerland. The project team identified seven mega-city regions (MCR) in north-west Europe and examined changes in functional connections and spatial relations indicated by information flows between and within the mega-city regions (Figure 2). The project established a Transnational Policy Network that aimed at promoting the development of cooperative plans to facilitate polycentricity and enhance interconnections at multiple levels of spatial development, policy making, and investment decisions.

China's city-cluster initiative took a top-down approach. A city-cluster region consists of multiple large or super-large cities along with an array of intermediate sized cities or counties and their hinterlands. The idea of accentuating future development in city-cluster regions began in China's 11th Five Year Socioeconomic Development Plan. As China moves into its 13th Five Year Socioeconomic Development Plan, developing a total of 19 city-clusters has become an essential component of the national urbanization strategy. As of mid-2019, the State Council has approved development plans for eight of the 19 city-cluster regions (Figure 3). The city-cluster plans set multiple economic and social development objectives; one of them aims at promoting balanced growth between regions 
and reducing disparities between the urban and rural areas in regions. The national railway plans in 2008 and 2016 officially stated the investment in HSR as an important infrastructure development strategy to implement the city-cluster regional plan [21].

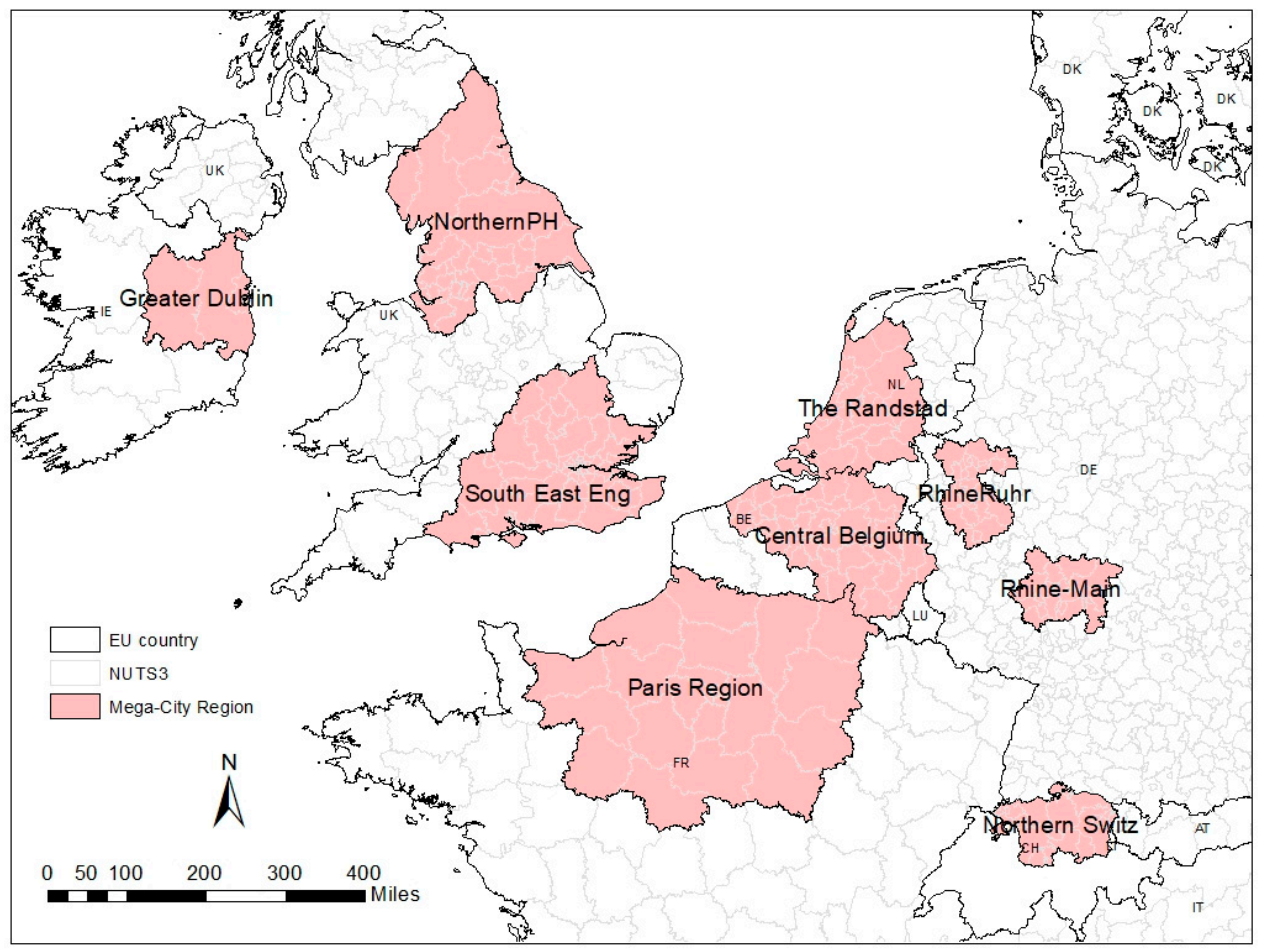

Figure 2. Nine Mega-City Regions in the Northeast Europe.

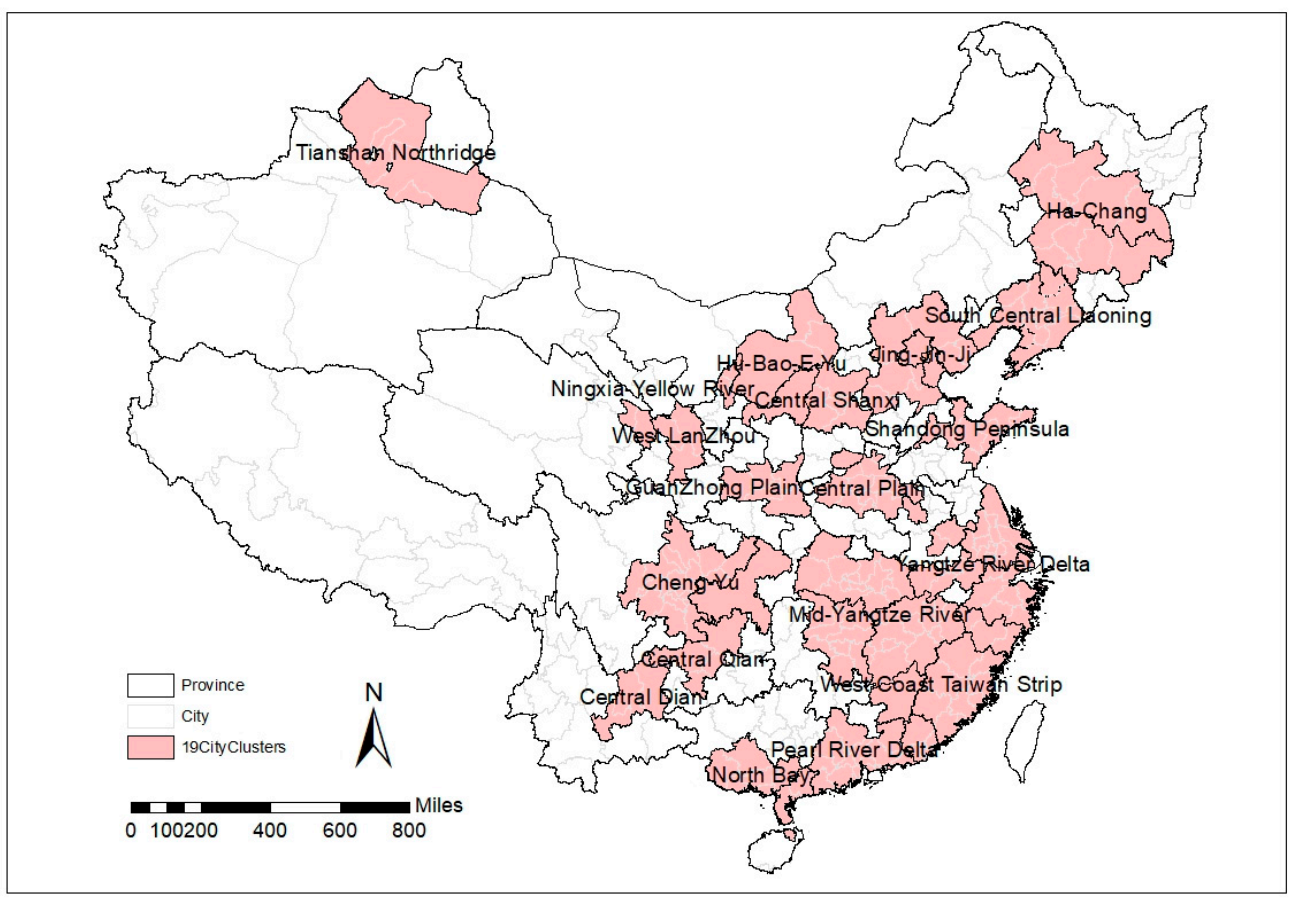

Figure 3. Nineteen City Clusters in China.

\subsection{Studies Concerning SI in General}

Depending on the standpoint of economic efficiency or social equity, SI may be viewed as a positive or a negative spatial phenomenon [3]. SI may appear positive if 
resulting from regional specialization with comparative advantages and returns to scale in production. On the other hand, SI may present social challenges if resulting from the spatial concentration of poverty, pollution, and decline. Recent interest in SI has grown out of the observed rising negative SI around the world [22]. International organizations such as the United Nations and the World Bank as well as many national and regional agencies have devoted effects to understand factors contributing to the growing negative SI and to identify intervention strategies, for instance, transportation infrastructure investments, to improve spatial equality.

Studies on regional economic inequality are mainly focused on characterizing the process of convergence (declining inequality) or divergence (increasing inequality). Empirical studies in the United States since the 1950s have shown an increase of systematic inequality, indicating the new shifts of economic growth on the regional basis [23]. Studies on personal and regional income distribution have indicated an inverted U-shaped inequality pattern-development within a region tends to diverge at the beginning period of the growth and then converge as the wealth accumulates [24,25]. The convergence/divergence conception has been applied to analyze spatial inequality as well. A variety of indices have been developed to quantify inequality and to investigate the spatial externality of the observed convergence/divergence [26]. Studies on megaregional SI were scarce, with a few exceptions $[27,28]$.

In the Chinese context, Wei (1999) examined the development trends in the preeconomic reform period (1949-1978) and the post-reform period (after 1978). He observed a declining regional inequality trend in the pre-reform period when the Central Government adopted balancing policies to distribute inter-regional resources. The post-reform period, however, witnessed an increasing regional inequality, especially a divergence between coastal areas and inner regions [29].

An essential feature of SI is multi-scalarity-SI varies by the spatial scale of geography where SI is addressed [22]. Existing studies have examined SI at the spatial scales varying by city sizes and by national and international territories [30-32]. This multi-scalarity makes the study of SI subject to the challenge of MAUP (Modifiable Area Unit Problem), which refers to the observation that analysis results of SI vary depending on the scale and composition of the geographic unit of analysis. Detailed examination on the nature of MAUP for SI goes beyond the scope of this paper. This study selects megaregions as the study scale consistent with the planning and policy interest in megaregions.

\subsection{Studies on HSR and SI}

HSR services shorten space-time distances and thus reshape the spatial access to opportunities over the built and natural environment. The technological and service characteristics of HSR determine that HSR's impacts do not distribute uniformly across the geography, but favor the locations near HSR stations and along the HSR lines. This raises questions concerning the distributional effects of HSR on reducing or worsening spatial inequality. Chen and Hall (2012) reported the European experience, suggesting that HSR might generate polarization effects around stations and HSR-rich cities. The polarization effects consequently increase inequality and disparity in multiple dimensions and spatial scales, for instance, between HSR- and non-HSR cities, among different socioeconomic and demographic groups, between cities of different sizes, and between different parts of territorial regions [33].

The European experience demonstrates that new HSR line may lead to redistribution of spatial access depending on how well the new lines are connected to existing conventional rail and other transportation systems. Martinez and Givoni (2012) argue that although the new High Speed 2 (HS2)reduced the travel time between London and several major cities in mid-north England, it didn't improve the accessibility for most cities around London and thus resulted in a less efficient spatial access due to the small number of HSR stations. 
Early studies on the effects of European HSR network and TEN reported an increased core-periphery imbalance across multiple countries [34,35]. While some cities benefited substantially from HSR, others became further marginalized due to the weak connection between the peripheral regions and the HSR cities. Accordingly, the authors stressed the importance of improving regional transport infrastructures to integrate the HSR stations with the rest of the region for augmenting the agglomeration effects of HSR.

Prime locations with direct HSR connectivity do not automatically lead to economic gains. Chen and Hall (2012), in their case study of HSR in France and the UK, showed that HSR services strengthened the economic performance of regional capitals that are specialized in knowledge-based economy. The old industrial regions, however, did not all regenerate successfully despite their direct access to HSR. Vickerman (2018) reported the redistribution of economic activities resulting from HS1 in the UK [36]. Communities along the HS1 line gained considerable benefits, while those located away from HS1 endured a decline. The observed HS1 impacts varied among different sectors; knowledge-based employment appeared to have significant gains attributable to HS1.

As HSR operations grow rapidly in China, the empirical evidence on HSR impacts is also growing. Research on spatial disparity in China confirms the positive impact of HSR on regional economic convergence, especially in the east and north due to the high network density. Decrease in accessibility disparity was evident most significantly within the central, southwest, and south of China [37-39]. Jiao et al. (2014) analyzed the accessibility effects by HSR and other ground transportation and observed increased inequality in three spatial dimensions: between the Eastern, Central, and Western regions of China, between extralarge, large, and small to medium sized cities, and between cities distant from and near HSR stations [40]. The same study also reported enlarged internal disparities with the regions attributable to HSR. Zhu et al. (2015) echoed the concerns of Jiao et al. (2014) from their analysis of HSR's accessibility effects for the years of 2009 and 2013. They showed the greater benefits enjoyed by the cities with direct HSR access versus those without HSR, and the cities in the prosperous eastern China versus those cities located in the hinterland [41]. Jiao et al. (2014) believed that the initial increase in SI resulting from the launch of HSR services would likely smooth out as the HSR network expands over time. Chen and Vickerman (2017) found that intra-regional inequality increased in the Yangtze River Delta Area (YRDA) of China [42]. The study confirmed what Martinez and Givoni (2012) observed in Europe, that lack of administrative collaboration and poor connectivity with HSR contributed to HSR associated intra-regional inequality.

Spatial inequality at the megaregional level under the influence of HSR deserves a focal attention, but has not yet been studied adequately. This study aims to expand the knowledge base in the area.

\section{Methods}

\subsection{Study Design and Data Sources}

There has been no consensus among scholars regarding megaregion definitions and delineations. We followed the definition by Regional Plan Association (RPA) for the eleven megaregions in the United States. For Europe, we adopted the definition of eight mega city regions in Hall and Pain (2006) and added the Northern Powerhouse from the Norther of England. The National Development and Reform Commission of China designated 19 city cluster regions in China. Assembling these delineations gave a total of 39 multicenter agglomerations (see Figures 1-3 above). For convenience, we refer to all of them as megaregions. Table 1 below shows the profiles of the 39 megaregions. No detailed economic and employment data needed for this study was available for Dublin MCR and Northern Switzerland MCR. These two regions were then excluded in the SI analysis and final reporting. 
Table 1. Megaregions Profiles, 2016.

\begin{tabular}{|c|c|c|c|c|}
\hline & Area km² & Population (Million) & $\begin{array}{c}\text { Number of } \\
\text { County/NUTS3/City }\end{array}$ & $\begin{array}{c}\text { Number of } \\
\text { MSA/FUA/City }\end{array}$ \\
\hline \multicolumn{5}{|c|}{ U.S. Megaregions (11) } \\
\hline Cascadia & 93,024 & 7.9 & 26 & 9 \\
\hline Florida & 81,932 & 15.1 & 32 & 13 \\
\hline Front Range & 159,297 & 7.7 & 37 & 9 \\
\hline Great Lakes & 387,885 & 47.2 & 279 & 51 \\
\hline Gulf Coast & 132,218 & 6.6 & 59 & 15 \\
\hline Northeast & 190,550 & 55.2 & 177 & 45 \\
\hline Northern CA & 105,763 & 13.3 & 28 & 15 \\
\hline Piedmont Atlantic & 164,974 & 18.2 & 127 & 18 \\
\hline Southern CA & 160,265 & 24.4 & 10 & 7 \\
\hline Sun Corridor & 208,881 & 6.0 & 10 & 4 \\
\hline Texas Triangle & 153,357 & 17.4 & 77 & 11 \\
\hline \multicolumn{5}{|c|}{ European Mega-City Regions (9) } \\
\hline South East England & 29,184 & 19.0 & 37 & 27 \\
\hline The Randstad & 8757 & 8.6 & 23 & 15 \\
\hline Central Belgium & 16,000 & 7.8 & 42 & 9 \\
\hline RhineRuhr & 11,536 & 11.7 & 25 & 4 \\
\hline Rhine-Main & 8211 & 4.2 & 19 & 5 \\
\hline Northern Switzerland & 13,700 & 3.5 & 3 & 5 \\
\hline Paris Region & 43,019 & 15.7 & 23 & 18 \\
\hline Greater Dublin & 7814 & 1.6 & 3 & 1 \\
\hline Northern Powerhouse & 37,142 & 10.7 & 56 & 12 \\
\hline \multicolumn{5}{|c|}{ China City-Cluster Regions (19) } \\
\hline Capital Zone (Jing-jin-ji) & 182,320 & 70.2 & 10 & 10 \\
\hline Yangtz River Delta & 200,056 & 117.7 & 25 & 25 \\
\hline Pearl River Delta & 109,170 & 43.0 & 13 & 13 \\
\hline Shandong Gulf & 73,192 & 39.7 & 8 & 8 \\
\hline Haixia West & 225,471 & 85.0 & 17 & 17 \\
\hline Shanxi Middle & 69,509 & 14.0 & 4 & 4 \\
\hline Zhongyuan & 99,690 & 68.4 & 13 & 13 \\
\hline Mid-Yangtze River & 349,829 & 121.2 & 28 & 28 \\
\hline Guanzhong & 72,958 & 23.9 & 5 & 5 \\
\hline Lanxi & 73,269 & 9.9 & 4 & 4 \\
\hline Hubaoeyu & 174,806 & 7.7 & 3 & 3 \\
\hline North Gulf & 98,705 & 36.0 & 9 & 9 \\
\hline Chengyu & 238,600 & 98.0 & 14 & 14 \\
\hline Qianzhou & 74,924 & 13.3 & 3 & 3 \\
\hline Ningxia & 13,156 & 2.6 & 3 & 3 \\
\hline Dianzhong & 64,852 & 14.3 & 3 & 3 \\
\hline Tianshan North & 190,612 & 2.2 & 2 & 2 \\
\hline Hachang & 322,559 & 45.2 & 10 & 10 \\
\hline Liao Middle south & 126,078 & 38.5 & 13 & 13 \\
\hline
\end{tabular}

The analysis carried out in this study contains two parts. Section 1 evaluates and compares SI for all 37 megaregions. This paper reports the results with two indicators of 
SI. One is the Theil index, which measures development inequality with data on gross regional products (GRP). We also calculated the Gini index and the Coefficient of Variation (CV) to assess megaregion SI. Due to space constraints, we present here only the results of the Theil index calculation. The results with Gini and CV are available upon request. The reason of using GRP instead of the commonly used income for SI assessment is twofold. First, GRP contains information on industrial economic accounts as well as household and government income. It provides a measure of regional development inequality that is better than income alone, while household or personal income serves better than GRP for measuring interpersonal inequality. Second, income data at the county or equivalent level was not available for China's megaregions.

The other indicator of SI that we used was the rank-size coefficient that characterizes the distribution of the urbanized areas of different sizes in a megaregion. We adopted this indicator from ESDP (1999) and Hall and Pain (2006) to quantify the degree of polycentricity of megaregions. Given the shared policy interest across countries and continents in balancing regional development, the degree of polycentricity offers a measure for comparing and monitoring the changes in agglomeration patterns of megaregions over time.

The data collected for this study all came from public sources. The European data at the NUTS3 level were collected from Euro Stat for the years of 2006 and 2016 [43]. For the U.S. megaregions, data on county-level population, employment, and GRP were compiled from American Community Survey (ACS), Business Dynamic Statistics, and Bureau of Economic Analysis [44,45]. Data on China's megaregions were extracted from China Urban Statistics Yearbooks for the study years [46].

The second part of the analysis zooms into three selected megaregions, one from each continent, and assesses changes in employment accessibility before and after the construction of HSR. The three selected megaregions include the Texas Triangle (USA), the Northern Powerhouse (NPh) (UK), and the Mid-Yangtze River City-Cluster Region (China). The selection of the three cases considered the observation that they share a similar spatial pattern of polycentric agglomeration. The Texas Triangle is spatially portrayed by three sets of anchor cities: Dallas-Ft. Worth to the north, Houston to the southeast, and Austin-San Antonio to the southwest. Similarly, the Mid-Yangtze River City-Cluster Region (China) is characterized by the capital cities of three provinces, Wuhan, Changsha, and Nanchang in a triangle setting. The region has thus earned the nickname of the Central Triangle in reference to the Yangtze Triangle (or Yangtze Delta) of the greater Shanghai in eastern China and the Pearl River Triangle (or the Pearl River Delta) of the Guangzhou-Shenzhen-Zhuhai area in southern China. The NPh region consists of five approximately equally sized cities and does not have a single dominant city like London in the south of England. Its regional spatial pattern also displays a triangular shape, with Newcastle located on the north apex and other cities aligned with the base lateral.

Furthermore, NPh and the Texas Triangle have a similar population size between 10 to 20 million. When measured by highway travel times, the Texas Triangle of USA and the Central Triangle of China display a similar dimension; the anchor cities of the triangle are all approximately three hours apart. The fact that all these three megaregions have either existing or proposed HSR operations makes them an interesting and comparable set of cases for this study.

The Texas Triangle is one of the eleven megaregions in the continental U.S. It is geographically encompassed by the metropolitan areas of Houston, Austin/San Antonio, and Dallas/Fort Worth (Figure 4). The region is expected to grow by an additional 10 million people over the next $40+$ years. This vast growth presents many challenges. Demand for consumption will be enormous on land, water, and other natural resources. The region's population will become more diverse, with a large amount of international in-migration, posing challenging demands for employment, education, health care, and other services. A third challenge is mobility. National mobility studies show that all the metro areas in the Texas Triangle have been among the nation's top congested regions in the past two decades. 
The region's transportation infrastructure needs major enhancement to keep people and goods moving.

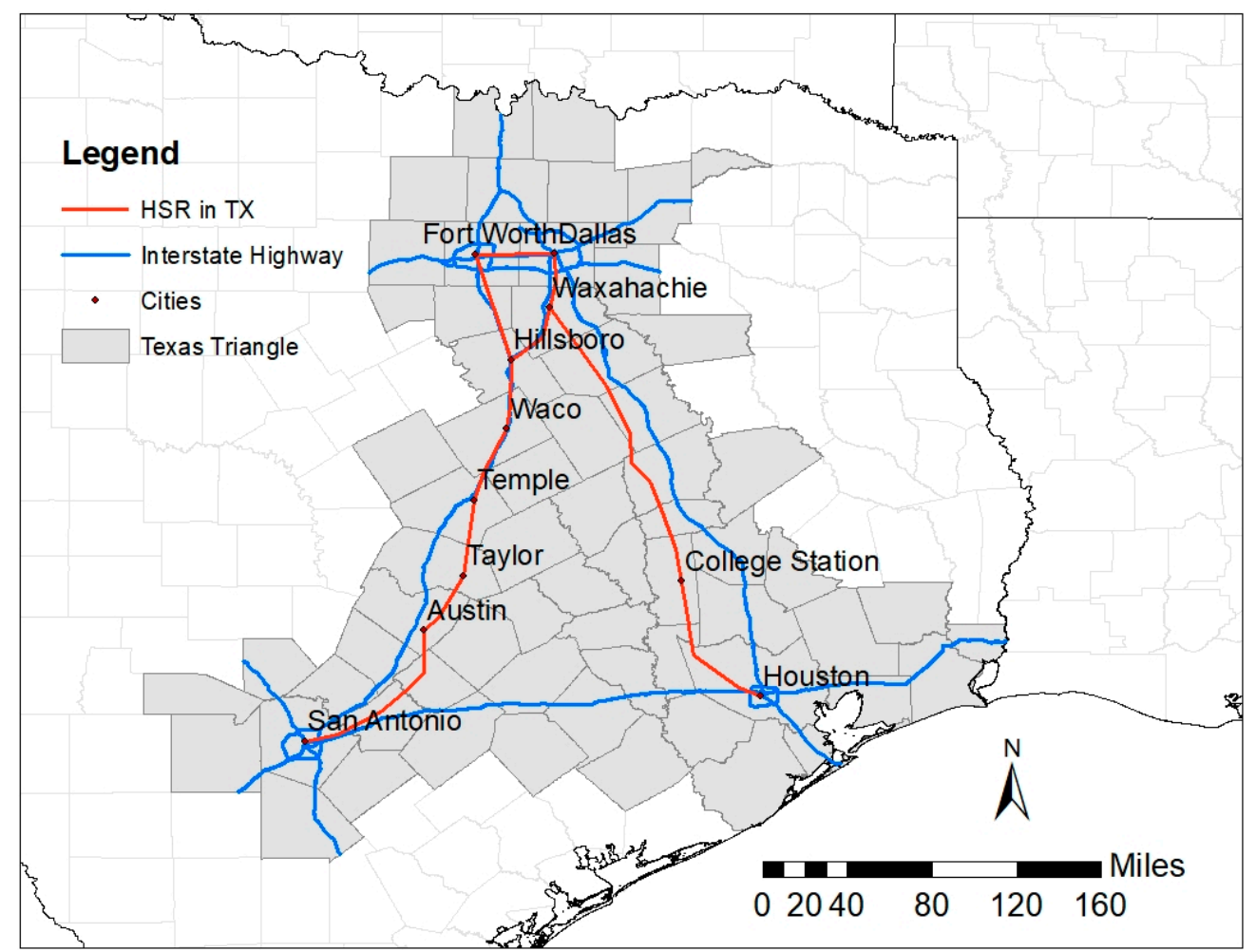

Figure 4. Texas Triangle Megaregion with Highway and Proposed HSR Network.

Currently, there are two HSR lines proposed for the Texas Triangle: The eastern HSR line being developed by a private company, Texas Central, connects Dallas to Houston in a length of 234 miles. The western line is a portion of the Texas-DOT/Oklahoma-DOT jointly proposed rail corridor, which runs 850 miles from Edmond/Oklahoma City, Oklahoma to Brownsville at the Texas-Mexico border. The central section of the line connects Dallas-Ft. Worth to San Antonio through Austin in a length of 247 miles.

The Northern Powerhouse (NPh) is an initiative aiming to strengthen the economic competitiveness of the North of England (Figure 5). The NPh initiative emerged as a response to the widening disparity between old industrial cities like Manchester, Leeds, Hull, Newcastle, and Liverpool in northern England and the South of England centered around London. One of the three proposed strategies is to boost high-speed rail links among $\mathrm{NPh}$ cities, fostering a competitive agglomeration comparable to the London region and other mega-city regions in Europe. HS2, a high-speed rail line currently under construction, connects London with Birmingham in Phase 1 and then to Manchester and Leeds in Phase 2. The proposed east-west rail in the North of England is often referred to as High-Speed Three (HS3), although the exact route has not been confirmed.

The Mid-Yangtze River City-Cluster Region, as the name stands, is in the middle range of the Yangtze River (Figure 6). The region encompasses 185 counties/cities in 28 prefectures from three provinces in central China, Hubei, Hunan, and Jiangxi. Three provincial capital cities form an approximate equilateral triangle with each side measured as 170 to 180 miles in airline distance. The region is known for offering rich resources in agricultural production, industrial and higher educational opportunities, multimodal transportation, and ecological resources. Wuhan, the capital city of Hubei Province, ranks \#5 by population nation-wide. Wuhan was the northern terminus of China's first long-haul HSR line connecting Wuhan and Guangzhou, the provincial capital of Guangdong; the line began commercial service in December 2009 in a route length of over 600 miles. Wuhan's 
position as China's HSR hub became prominent in 2012 when the Beijing-Wuhan HSR route (750 miles) was completed.

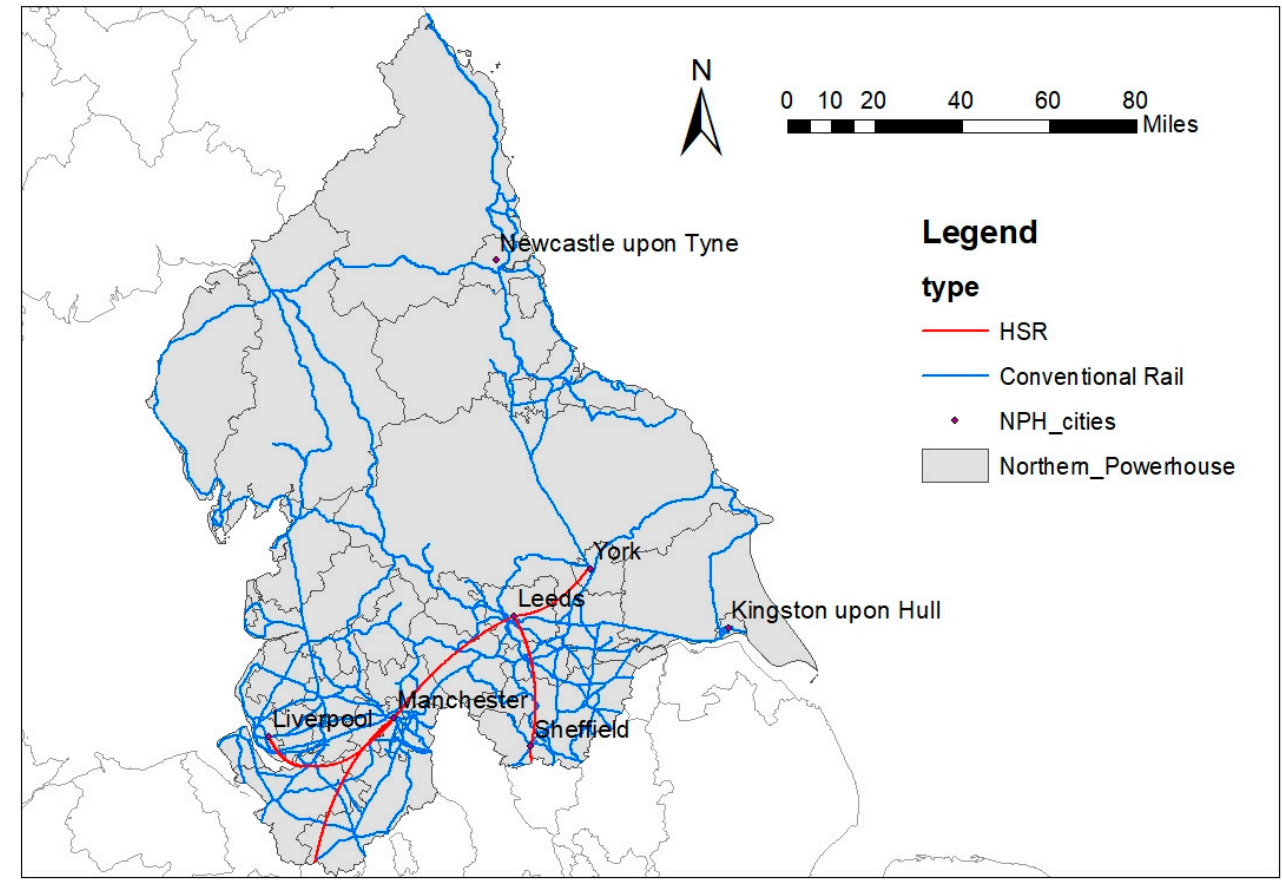

Figure 5. Northern Powerhouse with Conventional Railway and Proposed HSR Network.

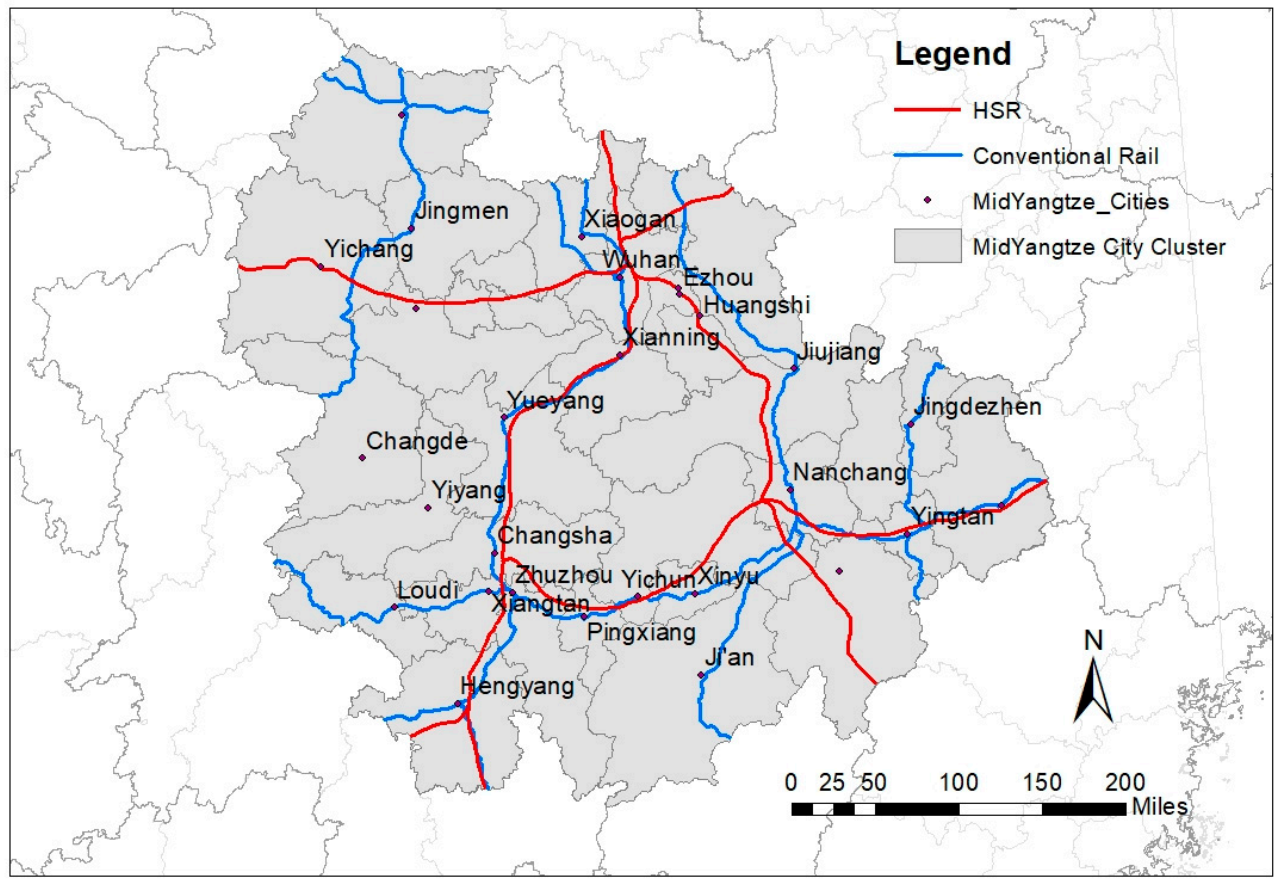

Figure 6. Mid-Yangtze River Megaregion with conventional railway and built HSR.

\subsection{Measures of Spatial Inequality}

Theil Index [47]

$$
T h=\sum_{i=1}^{m} n_{i} \frac{y_{i}}{\bar{y}} \ln \left(\frac{y_{i}}{\bar{y}}\right)
$$

where $m$ is number of geographic units in the megaregion; 
$y_{i}$ is average income/employment opportunity per person in geographic unit $i$;

$\bar{y}$ is average income/employment opportunity per person in the megaregion;

$n_{i}$ : percent of population in geographic unit $i$ over total population in the megaregion;

Degree of Polycentricity

Rank size rule is a model of urban hierarchies. It describes the rank and size relationship in the following form:

$$
\text { Rank }=K \frac{1}{\text { Size }}
$$

Taking a log transformation gives a linear Equation (3):

$$
\log (\operatorname{Rank})=\log (K)-\alpha \log (\text { Size })
$$

where Size is the population of an urbanized area and Rank indicates the position of the urbanized area in the rank order by the population size of all urbanized areas in the megaregion. $K$ is a constant. $\alpha$, the rank-size coefficient to be estimated with local data, measures the spatial structural characteristics of the megaregion. A smaller value of $\alpha$ (in absolute terms) indicates a higher degree of polycentricity [20].

Accessibility

The study applies a commonly used gravity model of accessibility. The model takes the following form:

$$
A_{i}^{Y}=\sum_{j} \frac{E_{j}^{Y}}{\left(T_{i j}^{Y}\right)^{\alpha}}
$$

where $A_{i}$ represents the accessibility of county $i ; E_{j}$ measures attractiveness at destination location $j$, and $T$ is travel time by rail between $i$ and $j . Y$ denotes the year in which $A$ is measured. The parameter $\alpha$ reflects travelers' sensitivity to time increase, which should be calibrated from the travel behavior observed in local regions. Due to the lack of the empirical data and for easy comparison across the cases, this study takes a value of 1 , a parameter value generally acceptable for the study purposes [48].

Destination attractiveness $E_{j}$ may take different value input, which then suggests $A$ being interpreted in different ways for specific analytical purposes. In this study, $E$ takes two types of data input, employment and GRP. For the accessibility calculated with employment, $A$ serves as a measure of the geography of opportunities, capturing HSR related agglomeration effects (The World Bank 2014). For the accessibility calculated with GRP, $A$ reads as a measure of market potential or the size of local/regional economy [49]. The results for accessibility with GRP are not reported in this paper and are available upon request.

\section{Study Results}

\subsection{Inequality in 37 Megaregions}

This part compares the trend of regional inequality in 37 megaregions between the years 2006 and 2016 (Table 2).

In Table 2, Chinese megaregions exhibited the highest SI among the three continents. In 2006, the Theil index values of China's 19 megaregions averaged 0.157, about two times or more of those for the U.S. megaregions ( 0.081$)$ and for the European mega city-regions (0.063), respectively. Ten years later in 2016, the average level of SI (0.132) in Chinese megaregions remained higher than those in the U.S. and European megaregions (0.087 and 0.069 , respectively). The high SI of Chinese megaregions relative to those in Europe and the United States may be explained by China's development stage and conditions. In China, rapid economic growth and urbanization likely concentrate wealth and jobs in large, central cities while the development in rural areas and remote regions lagged behind. In 2016, China's megaregion SI declined from that in 2006. The study results appear consistent with the convergence/divergence theory, which suggests that fast-growing economies tend to experience a high level of inequality in the initial stage of development; as the 
economy continues to grow, inequality decreases gradually [50,51]. Contrasting with China's megaregion SI trend, the average level of SI increased slightly between 2006 and 2016 in the U.S. and European megaregions where the Theil index rose from 0.081-0.087 and from $0.063-0.069$, respectively.

Table 2. Regional Inequality Change in 37 Megaregions.

\begin{tabular}{|c|c|c|c|}
\hline & \multicolumn{3}{|c|}{ Theil (GRP) } \\
\hline & 2006 & 2016 & Change \\
\hline \multicolumn{4}{|c|}{ U.S. Megaregions } \\
\hline Cascadia & 0.076 & 0.099 & $30 \%$ \\
\hline Florida & 0.030 & 0.039 & $32 \%$ \\
\hline Front Range & 0.059 & 0.057 & $-4 \%$ \\
\hline Great Lakes & 0.051 & 0.051 & $-1 \%$ \\
\hline Gulf Coast & 0.143 & 0.084 & $-41 \%$ \\
\hline Northeast & 0.197 & 0.224 & $14 \%$ \\
\hline Northern CA & 0.071 & 0.136 & $91 \%$ \\
\hline Piedmont Atlantic & 0.139 & 0.132 & $-5 \%$ \\
\hline Sourthern CA & 0.019 & 0.026 & $34 \%$ \\
\hline Sun Corridor & 0.029 & 0.031 & $7 \%$ \\
\hline Texas Triangle & 0.072 & 0.075 & $4 \%$ \\
\hline Average & 0.081 & 0.087 & $15 \%$ \\
\hline \multicolumn{4}{|c|}{ European Mega-City Regions } \\
\hline Central Belgium & 0.064 & 0.058 & $-9 \%$ \\
\hline NorthernPH* & 0.034 & 0.037 & $8 \%$ \\
\hline Paris Region & - & 0.159 & - \\
\hline Rhine-Main & 0.133 & 0.103 & $-23 \%$ \\
\hline RhineRuhr & 0.080 & 0.067 & $-17 \%$ \\
\hline South East Eng * & 0.016 & 0.014 & $-11 \%$ \\
\hline The Randstad & 0.053 & 0.047 & $-9 \%$ \\
\hline Average & 0.063 & 0.069 & $-10 \%$ \\
\hline \multicolumn{4}{|c|}{ China City-Clusters Regions } \\
\hline Beibu Gulf & 0.043 & 0.065 & $50 \%$ \\
\hline Capital Zone & 0.199 & 0.236 & $18 \%$ \\
\hline Central of Dian & 0.090 & 0.104 & $16 \%$ \\
\hline Central Plains & 0.140 & 0.165 & $18 \%$ \\
\hline Central Qian & 0.137 & 0.130 & $-5 \%$ \\
\hline Central Shanxi & 0.149 & 0.145 & $-3 \%$ \\
\hline Central South of Liao & 0.113 & 0.149 & $32 \%$ \\
\hline Chengyu & 0.110 & 0.097 & $-12 \%$ \\
\hline Guanzhong Plains & 0.109 & 0.079 & $-28 \%$ \\
\hline Hachang & 0.166 & 0.083 & $-50 \%$ \\
\hline Hubaoeyu & 0.157 & 0.066 & $-58 \%$ \\
\hline Lanxi & 0.197 & 0.211 & $7 \%$ \\
\hline Mid-Yangtze River & 0.146 & 0.182 & $24 \%$ \\
\hline Ningxia & 0.027 & 0.021 & $-22 \%$ \\
\hline North Foot of Tianshan & 0.237 & 0.045 & $-81 \%$ \\
\hline Pearl River Delta & 0.539 & 0.407 & $-24 \%$ \\
\hline Shandong Peninsula & 0.071 & 0.050 & $-29 \%$ \\
\hline West Shore & 0.165 & 0.139 & $-16 \%$ \\
\hline Yangzte Delta River & 0.183 & 0.132 & $-28 \%$ \\
\hline Average & 0.157 & 0.132 & $-10 \%$ \\
\hline
\end{tabular}

* Note: For two MCRs in the U.K., Northern Powerhouse and Southeast England, we used regional GVA to calculate Theil Index due to lack of GRP data.

Variations exist in the levels of SI between individual megaregions within each continent. In the United States, the Northeast megaregion had the highest level of SI in 2016. Northern California outpaced other U.S. megaregions in terms of SI growth $(91 \%$ increase in its Theil index) from 2006-2016. Cascadia also had a rather high level of SI as indicated by its Theil index of 0.099 in 2016, showing a 30\% increase from 2006. These three megaregions have high concentrations of finance and high-tech jobs with high salaries, contributing to the high levels and rates of growth in SI [52]. Piedmont Atlantic also had a high level of SI, yet its Theil index did not change much between 2006 and 2016. In Europe, Paris Region had the highest Theil index of 0.159 among the seven mega city regions in 
2016. A longitudinal study by Roses and Sanchis showed that French regional income inequality decreased slowly from 1860 until 1982 and then moved upward, led by the outstanding dominance of Paris Region [53]. A recent study on Paris Region identified the latest increase in income inequality in Paris Region being driven by rising wages among the top 1\% earners [54]. Among the six European mega city regions where data were available, Northern Powerhouse stood out as the only one that saw an increase in the SI index between 2006 and 2016. The Northern Powerhouse initiative was introduced in response to the widening gap between the North and the South of England. It is also critical to address the increasing within-region inequality as indicated by this study's result. In China, seven of the 19 city-cluster regions experienced an increase in SI over the ten-year period of 2006-2016. The top two regions with the highest Theil Index in 2016 were two growth engines of China, Pearl River Delta and Capital Zone (Beijing, Tianjin and Hebei).

\subsection{Polycentricity of Megaregions}

Table 3 report estimated rank-size coefficients as measures of megaregion polycentricity. For the US megaregions, changes in the rank-size coefficients from 2006-2016 appeared positive; the trend lines became steeper, indicating a trend towards a less polycentric built environment. However, the magnitude of changes is rather small. Changes in the European mega-city regions were also small, but more diverse than in the U.S. megaregions. RhineMain, Paris Region, and Northern Switzerland moved slightly toward less polycentric, whereas Central Belgium, RhineRuhr, the Randstad, and South East England increased in the degree of polycentricity. Changes in China's city-cluster regions show a great deal of dynamics: those located in western China, for instance, Ningxia, Central Shanxi, Tianshan Northridge, and Chengyu saw the biggest increase in their rank-size coefficients. It means that primary cities have increased their primacy in their respective regions, a phenomenon commonly seen in the early stage of fast urbanization.

Table 3. Dynamic Changes of Polycentricity of 37 Megaregions.

\begin{tabular}{|c|c|c|c|}
\hline & \multicolumn{3}{|c|}{ Rank-Size Coefficient } \\
\hline & 2006 & 2016 & Change \\
\hline \multicolumn{4}{|c|}{ U.S. Megaregions } \\
\hline Southern CA & -1.525 & -1.525 & $0.0 \%$ \\
\hline Northern CA & -1.047 & -1.059 & $1.1 \%$ \\
\hline Piedmont Atlantic & -1.400 & -1.427 & $1.9 \%$ \\
\hline Great Lakes & -1.318 & -1.325 & $0.5 \%$ \\
\hline Sun Corridor & -2.489 & -2.524 & $1.4 \%$ \\
\hline Front Range & -1.400 & -1.409 & $0.6 \%$ \\
\hline Gulf Coast & -0.983 & -0.992 & $0.9 \%$ \\
\hline Texas Triangle & -1.735 & -1.751 & $0.9 \%$ \\
\hline Florida & -1.034 & -1.036 & $0.2 \%$ \\
\hline Cascadia & -1.518 & -1.534 & $1.1 \%$ \\
\hline Northeast & -1.187 & -1.187 & $0.0 \%$ \\
\hline Average & -1.421 & -1.434 & $0.9 \%$ \\
\hline Standard deviation & 0.481 & 0.492 & 0.021 \\
\hline \multicolumn{4}{|c|}{ European Mega-City Regions * } \\
\hline Central Belgium & -1.421 & -1.219 & $-14 \%$ \\
\hline Northern Powerhouse & -1.201 & -1.201 & $0 \%$ \\
\hline Northern Switzerland & -1.420 & -1.474 & $4 \%$ \\
\hline Rhine-Main & -1.143 & -1.152 & $1 \%$ \\
\hline RhineRuhr & -1.192 & -1.185 & $-1 \%$ \\
\hline Paris Region & -1.455 & -1.485 & $2 \%$ \\
\hline The Randstad & -1.241 & -1.334 & $-27 \%$ \\
\hline South East England & -1.651 & -1.213 & $-14 \%$ \\
\hline Average & -1.341 & -1.283 & $-3 \%$ \\
\hline Standard deviation & 0.174 & 0.132 & 0.113 \\
\hline
\end{tabular}


Table 3. Cont.

\begin{tabular}{cccc}
\hline & \multicolumn{2}{c}{ Rank-Size Coefficient } \\
& $\mathbf{2 0 0 6}$ & $\mathbf{2 0 1 6}$ & Change \\
\hline China City-Cluster Regions & \\
\hline Beibu Gulf & -0.836 & -0.984 & $17.7 \%$ \\
Capital Zone (Jing-jin-ji) & -1.500 & -1.468 & $-2.1 \%$ \\
Central of Dian & & & $76.1 \%$ \\
Central Plains & -0.748 & -1.317 & $-41.2 \%$ \\
Central Qian & -0.915 & -0.538 & $-0.7 \%$ \\
Central Shanxi & -1.601 & -1.590 & $3.6 \%$ \\
Central South of Liao & -0.839 & -0.869 & $-1.3 \%$ \\
Chengyu & -1.101 & -1.087 & $7.1 \%$ \\
Guanzhong Plains & -1.301 & -1.394 & $7.5 \%$ \\
Hachang & -1.051 & -1.130 & $-7.6 \%$ \\
Hubaoeyu & -0.898 & -0.830 & $-2.2 \%$ \\
Lanxi & -1.157 & -1.132 & $-0.3 \%$ \\
Mid-Yangtze River & -0.735 & -0.733 & $100.1 \%$ \\
Ningxia & -0.680 & -1.361 & $21.2 \%$ \\
North Foot of Tianshan & -2.579 & -3.127 & $-7.0 \%$ \\
Pearl River Delta & -1.173 & -1.091 & $-9.3 \%$ \\
Shandong Peninsula & -0.805 & -0.730 & $-12.7 \%$ \\
West Shore & -0.987 & -0.862 & $-1.7 \%$ \\
Yangtz River Delta & -0.945 & -0.929 & $6.6 \%$ \\
Average & -0.761 & -0.811 & 0.220 \\
Standard deviation & 0.493 & 0.603 & \\
\hline
\end{tabular}

* Note: The 2006 population data for European MCRs was not available at the Functional Urban Area level. We used the data for 2010 instead.

Figure 7 illustrates the rank size distribution of cities in Texas Triangle, Northern Powerhouse, and Mid-Yangtze River. The three megaregions were selected for the close-up analysis of HSR impacts on accessibility presented in the following section.

\section{Texas Triangle}

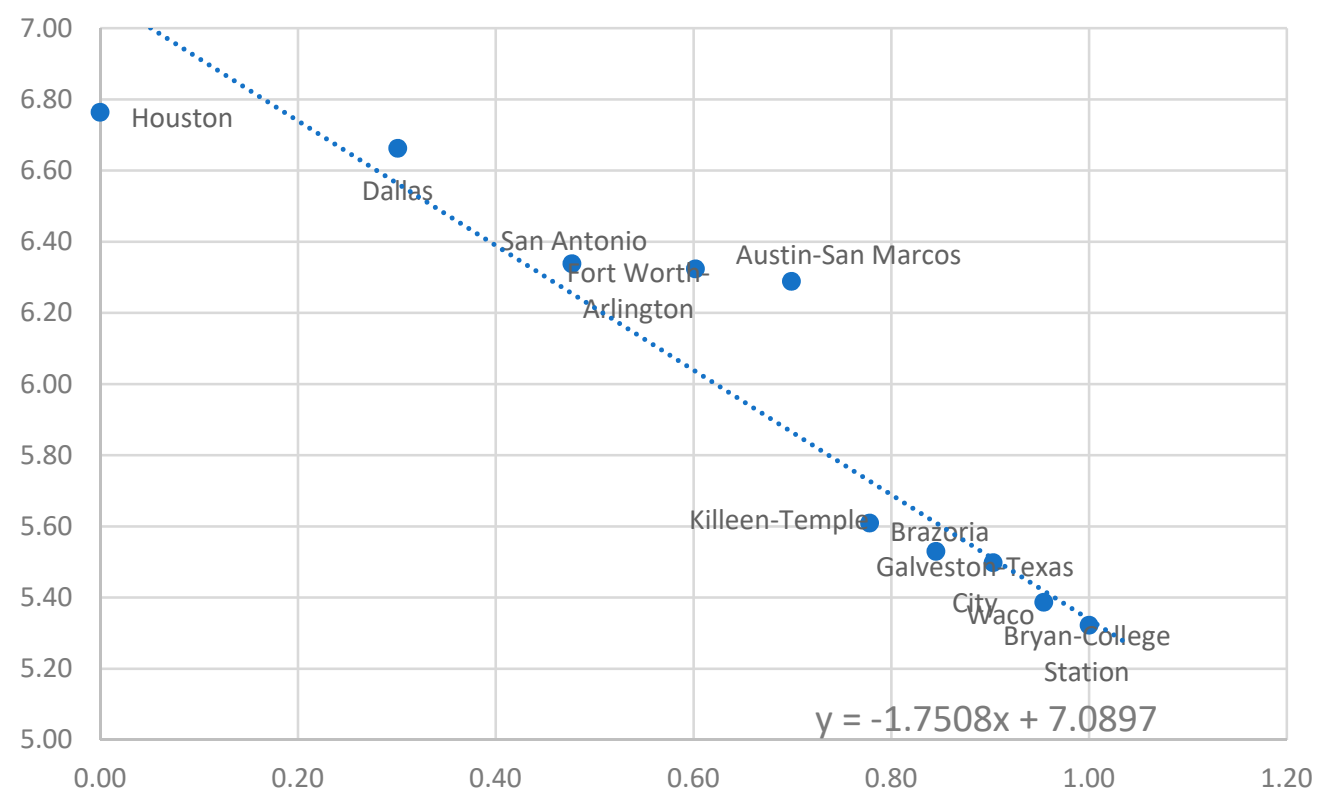

Figure 7. Cont. 
Northern Powerhouse

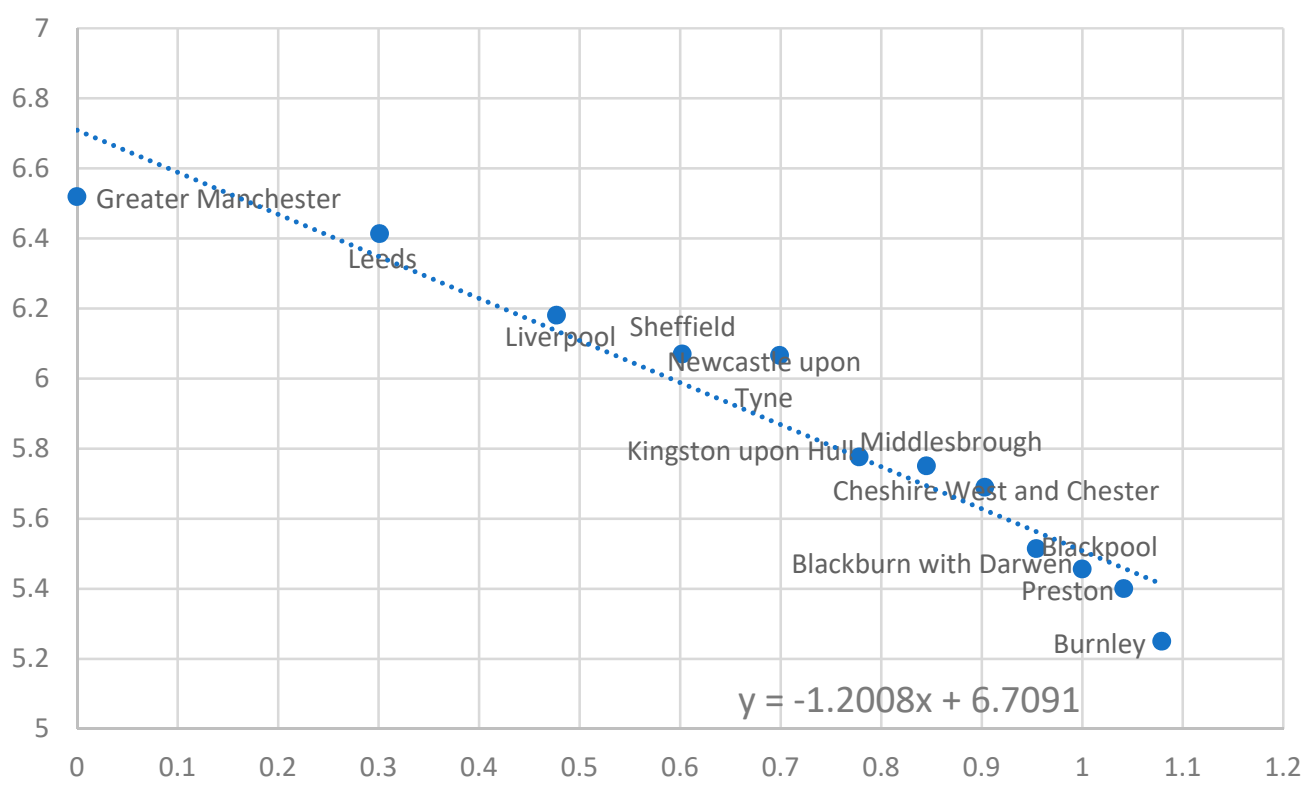

Mid Yangtze River

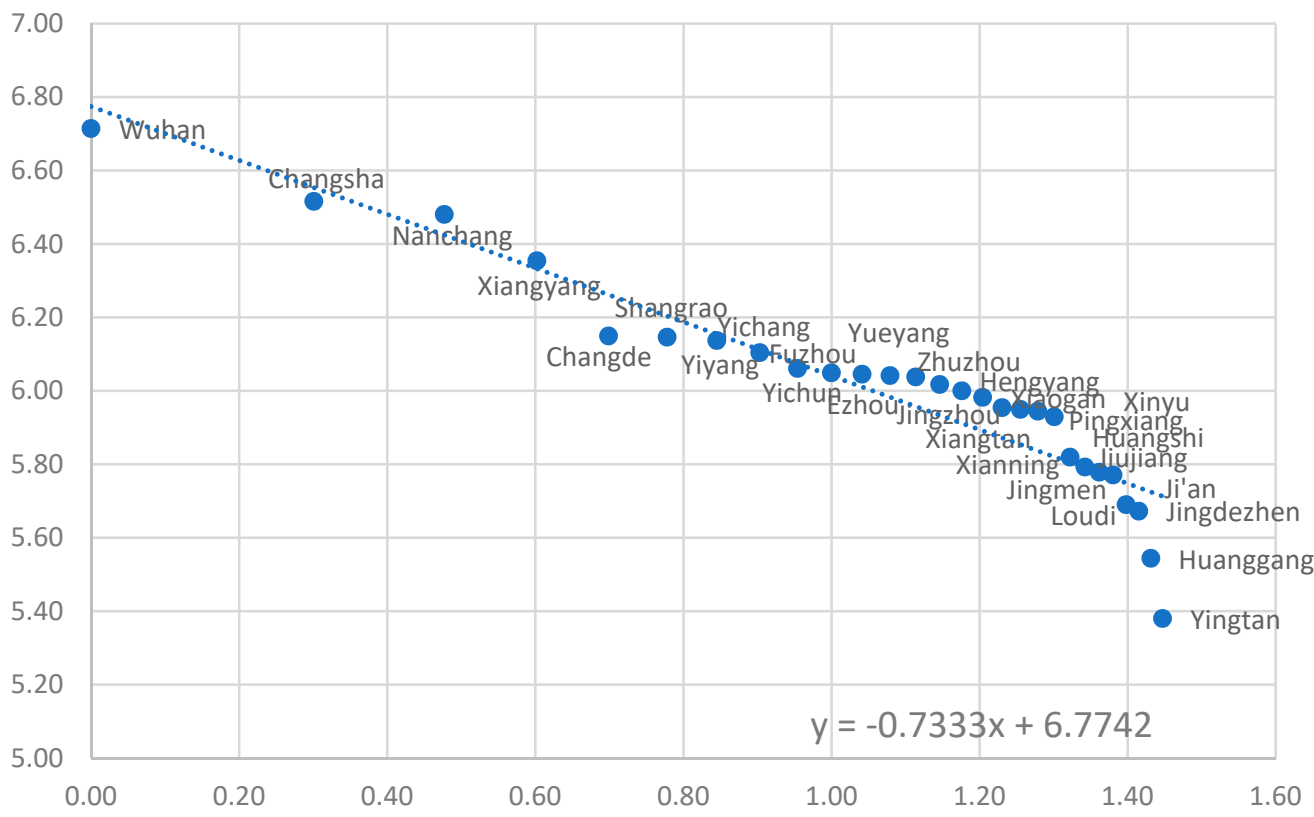

Figure 7. Rank size distribution of cities in three megaregions, 2016.

\subsection{HSR Impact on Regional Inequality}

HSR improves mobility among cities and regions. Better mobility can increase access to job opportunities. At the same time, HSR may modify the distribution of access in such a way that the gap widens between those areas with HSR access and those without. This part of the analysis chooses three megaregions from UK, USA, and China to examine the distributional effects on job accessibility caused by the built or proposed HSR lines. In the Northern Powerhouse, there are two proposed HSR phases, HS2 as the main artery connecting London from the south to Manchester and Leeds via Shefield. HS3 as a horizontal line contributes a better connection from Liverpool to Leeds. In the Texas Triangle, there were two proposed HSR lines, the Dallas-Houston (DAL-HOU) HSR and the Dallas-Austin-San Antonio HSR, connecting two edges of the triangle. In the Mid-Yangtze River, each of 
the three anchor cities, Wuhan, Changsha, and Nanchang has two or more HSR lines that connect them with 25 other cities in the region and with other cities in the rest of China.

The accessibility measured in the three megaregions are based on employment at the city/metropolitan level. In the Texas Triangle, the before and after accessibility were calculated for 11 cities in the megaregion, all with a proposed HSR terminal/intermediate station. In the Mid-Yangtze River, it included 28 prefecture-level cities and in NPh, the accessibility was calculated for 6 major cities.

Table 4 reports the results of accessibility modeling for the three megaregions for the scenarios of No-HSR and With-HSR. Overall, the Texas Triangle and the Northern Powerhouse all experience increase in accessibility associated with the proposed HSR services, although the magnitude of accessibility gains varies among individual cities and metropolitan areas. The picture for the Mid-Yangtze River city-cluster region looks somewhat complex. Most of the region's cities enjoyed an increase in employment-based accessibility.

Table 4. Employment-based accessibility change before and after HSR.

\begin{tabular}{|c|c|c|c|c|c|c|c|}
\hline & No HSR & With HSR & Change & & No HSR & With HSR & Change \\
\hline \multicolumn{4}{|c|}{ Mid-Yangtze River } & \multicolumn{4}{|c|}{ Texas Triangle } \\
\hline Xiangyang & 31,444 & 45,792 & $45.6 \%$ & Dallas & 38,064 & 67,551 & $77.5 \%$ \\
\hline Jingmen & 42,712 & 59,904 & $40.3 \%$ & Fort Worth & 53,648 & 85,056 & $58.5 \%$ \\
\hline Jingzhou & 47,102 & 76,705 & $62.8 \%$ & Waxahachie & 37,357 & 87,765 & $134.9 \%$ \\
\hline Xiaogan & 55,461 & 112,368 & $102.6 \%$ & Hillsboro & 64,743 & 120,924 & $86.8 \%$ \\
\hline Wuhan & 46,855 & 102,032 & $117.8 \%$ & Waco & 51,871 & 96,300 & $85.7 \%$ \\
\hline Yichang & 34,887 & 61,990 & $77.7 \%$ & Temple & 50,377 & 99,713 & $97.9 \%$ \\
\hline Ezhou & 111,020 & 162,185 & $46.1 \%$ & Taylor & 51,311 & 112,122 & $118.5 \%$ \\
\hline Xianming & 123,351 & 147,671 & $19.7 \%$ & Austin & 39,207 & 72,675 & $85.4 \%$ \\
\hline Huanggang & 68,662 & 107,103 & $56.0 \%$ & San Antonio & 28,588 & 50,433 & $76.4 \%$ \\
\hline Huangshi & 55,332 & 115,943 & $109.5 \%$ & $\begin{array}{l}\text { College } \\
\text { Station }\end{array}$ & 47,260 & 63,301 & $33.9 \%$ \\
\hline Yueyang & 51,160 & 122,598 & $139.6 \%$ & Houston & 21,069 & 38,611 & $83.3 \%$ \\
\hline Changde & 32,303 & 55,480 & $71.8 \%$ & \multicolumn{4}{|c|}{ Northern Powerhouse } \\
\hline Changsha & 47,612 & 124,271 & $161.0 \%$ & Manchester & 25,401 & 34,356 & $35.3 \%$ \\
\hline Zhuzhou & 53,766 & 150,023 & $179.0 \%$ & Liverpool & 20,709 & 24,597 & $18.8 \%$ \\
\hline Pingxiang & 119,079 & 130,073 & $9.2 \%$ & Leeds & 23,942 & 36,318 & $51.7 \%$ \\
\hline Hengyang & 106,015 & 90,119 & $-15.0 \%$ & Sheffield & 25,211 & 32,061 & $27.2 \%$ \\
\hline Xiangtan & 46,408 & 92,030 & $98.3 \%$ & Hull & 18,897 & 20,387 & $7.9 \%$ \\
\hline Yiyang & 76,851 & 72,118 & $-6.2 \%$ & Newcastle & 12,469 & 14,574 & $16.9 \%$ \\
\hline Yichun & 121,572 & 129,553 & $6.6 \%$ & & & & \\
\hline Nanchang & 78,209 & 92,649 & $18.5 \%$ & & & & \\
\hline Xinyu & 61,995 & 102,597 & $65.5 \%$ & & & & \\
\hline Fuzhou & 36,782 & 77,631 & $111.1 \%$ & & & & \\
\hline Loudi & 60,229 & 54,239 & $-9.9 \%$ & & & & \\
\hline Jiujiang & 163,985 & 61,924 & $-62.2 \%$ & & & & \\
\hline Yingtan & 75,581 & 64,861 & $-14.2 \%$ & & & & \\
\hline Shangrao & 46,066 & 44,178 & $-4.1 \%$ & & & & \\
\hline Jian & 39,873 & 41,413 & $3.9 \%$ & & & & \\
\hline Jingdezhen & 19,091 & 33,040 & $73.1 \%$ & & & & \\
\hline
\end{tabular}

To better illustrate the changes in accessibility associated with HSR, Figure 8 maps out the accessibility surfaces for the megaregions in the three continents. 


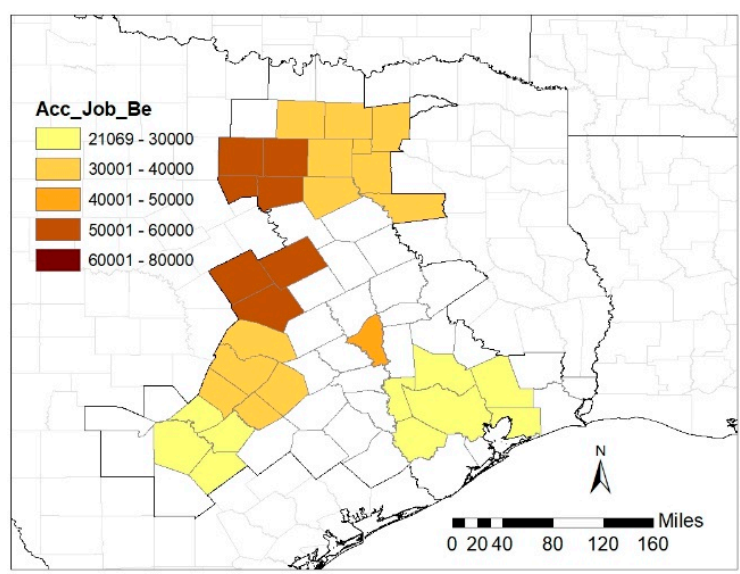

(a)

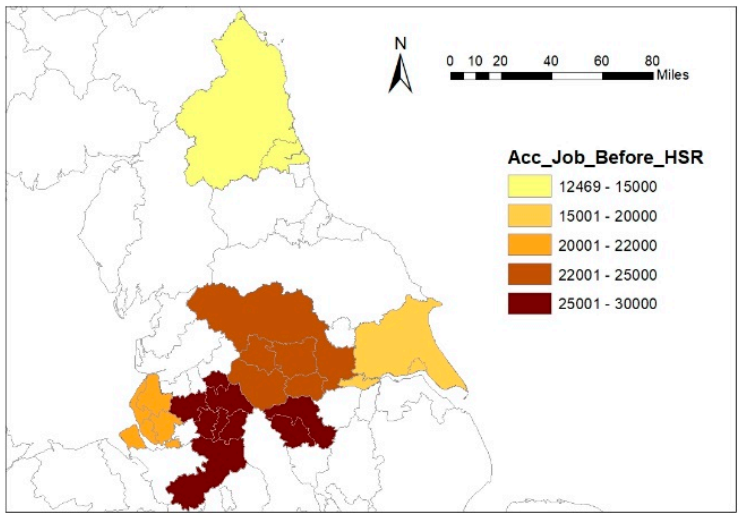

(c)

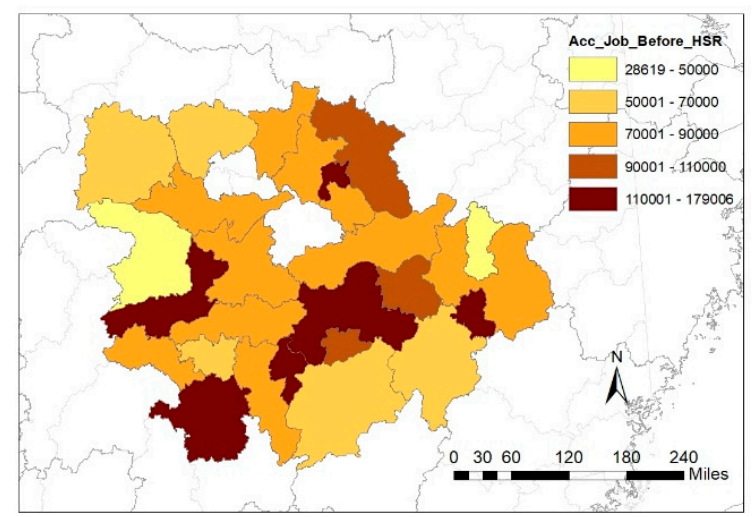

(e)

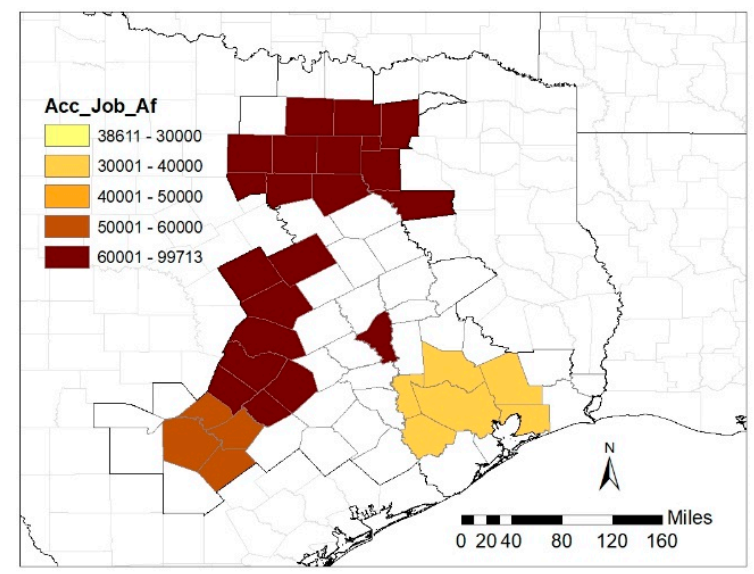

(b)

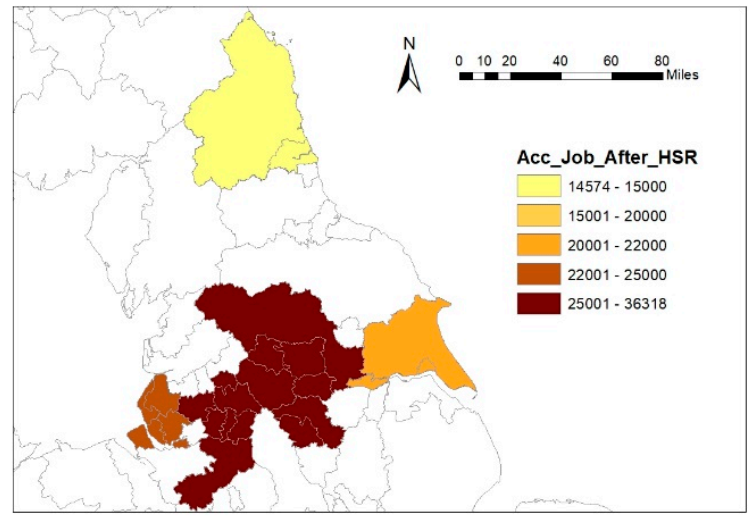

(d)

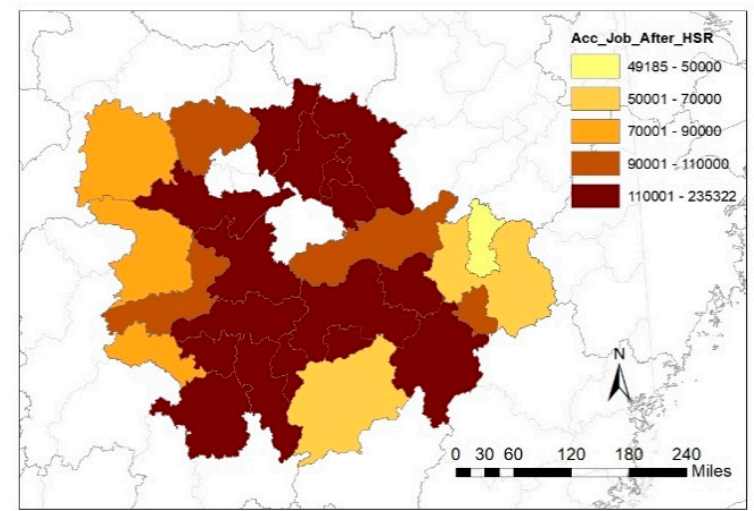

(f)

Figure 8. Job Accessibility without (left) vs. with (right) HSR in Texas Triangle (a,b), Northern Powerhouse (c,d), and Mid-Yangtze River (e,f).

\subsection{SI Changes Measured by Accessibility}

Table 5 below reports the levels of SI measured by the Theil Index of job accessibility and SI changes before and after HSR in the Texas Triangle, the Northern Powerhouse, and the Mid-Yangtze River. In the No-HSR scenario, both Texas Triangle and the Northern Powerhouse have relative low values of Theil Index (0.047 and 0.018, respectively), suggesting that job accessibility is fairly evenly distributed in each of the two megaregions. For the With-HSR scenario, job accessibility increases more in the cities served by HSR than in the cities with no HSR stations. The Theil Index becomes higher $(0.055$ and 0.033 , respectively), capturing the spatially differentiated impacts of HSR on megaregional job 
accessibility. Figures 7 and 8 suggest a pattern of spatial corridorization or polarization in HSR associated job access changes in the two megaregions.

Table 5. Inequality of employment-based accessibility before and after HSR (Theil Index).

\begin{tabular}{cccc}
\hline & No HSR & With HSR & Change (\%) \\
\hline Texas Triangle & 0.047 & 0.055 & $17 \%$ \\
The Northern & 0.018 & 0.033 & $83 \%$ \\
Powerhouse & 0.106 & 0.072 & $-32 \%$ \\
Mid-Yangtze River & & & \\
\hline
\end{tabular}

In the Mid-Yangtze River of China, the Theil Index of job accessibility is relatively high at 0.106 with no HSR. The index value drops by $32 \%$ to 0.072 when there is HSR. HSR affects the distribution of job accessibility in the Mid-Yangtze River in the opposite direction to that in the Texas Triangle and the Northern Powerhouse. This difference of HSR effects can be attributed to the difference in the coverage of HSR routes and stations among the three megaregions. In the Texas Triangle, the proposed HSR routes are limited to two corridors between Dallas-Ft. Worth and Houston and between Dallas-Ft. Worth and Austin-San Antonio. The Dallas-Houston corridor has only one intermediate station. In the Northern Powerhouse, the HSR route connects only the major cities in the south, leaving Newcastle upon Tyne and Kingston upon Hull off. Contrastingly, HSR network in the Mid-Yangtze River connects the capital cities of three provinces as well as 25 medium or small sized cities in the region.

\section{Conclusions}

Amid growing concerns over the rising spatial inequality and the widespread interest in megaregions around the world, this paper presents an effort to benchmark the conditions and trends of spatial inequality in 37 world megaregions. The study measured spatial inequality with the Theil index of GRP and with the rank-size coefficient of polycentricity. Furthermore, the study selected three megaregions, one from each continent, and assessed the role of HSR in reshaping SI in terms of access to jobs. Three conclusions can be drawn from the study results.

First, spatial inequality exists and varies in magnitude within and between megaregions in the United States, Europe, and China. On average, Chinese megaregions exhibited a level of spatial inequality about two times or more of those in the U.S. and European megaregions. However, the decade between 2006 and 2016 saw a decrease in the Theil index measure of megaregional inequality in China, but a slight increase in the United States and Europe. The study's findings on megaregional inequality show consistency with what the convergence/divergence theory suggests and with the findings reported from inequality studies at interpersonal or other spatial scales. Fast growing megaregions exhibit high levels of spatial inequality regardless of the country or continent setting, for instance, in Northern California of the United States, Paris Region of Europe, and the Beijing-Tianjin-Hebei city cluster of China. The rising spatial inequality in these regions has been driven largely by the dominance of superstar cities such as San Francisco, Paris, and Beijing.

Second, megaregions offer a new and promising spatial approach to address inequality challenges. Megaregions cross multiple municipal or national boundaries. A megaregional approach to SI helps uncover the disparity between fast growing, affluent core cities, and the by-passed, underperforming communities in a territory beyond the boundaries of individual municipalities and jurisdictions. The European Spatial Development Perspective, the Northern Powerhouse Initiative, and China's City-Cluster Development Program are examples of cross-jurisdiction (cross-country), megaregional approach to promote balanced development and reduce inequality. This emphasis on megaregional scale is not to diminish the importance of within-city inequality, but to voice that focusing only on the dominant cities likely masks the worsening SI in a broad spatial dimension. 
Third, the quantity and quality of transportation and other regional infrastructure are critical determinants of spatial wellbeing as they improve access to opportunities. HSR helps improve mobility and accessibility. Yet, the extent to which HSR reduces spatial inequality is context dependent. HSR elevates mobility by reducing travel times. Its role in reducing spatial inequality is contingent on the geographic coverage of HSR network, the pre-existing level of mobility of the served region, and the integration with other transportation systems to reach non-HSR locations. HSR offers fast and reliable travel advantages over other travel means for a medium distance range of 100 to 500 miles. Its technological features make it inefficient economically and operationally to connect every part of the region. As the study results for the Texas Triangle and the Northern Powerhouse show, HSR's polarization and corridor effects likely differentiate the places with direct HSR linkage from others without. The resulting impacts can widen spatial inequality especially in regions where HSR is newly introduced with a limited service coverage.

This paper presents a first attempt to monitor spatial inequality conditions and trajectories in world megaregions and to analyze factors (HSR in this case) contributing to or modifying SI. The current work warrants further expansions in several directions. It is important to include megaregions or similar geographies from other parts of the world, for instance, the rest of Asia and countries in the Global South where mega-city regions also exist or are emerging. In addition, the analysis should be expanded to consider other intervention policies and investments strategies aside from HSR. The SI issue is complex and deserves in-depth investigation with data in higher spatial resolutions, and it should be closely examined along social and economic dimensions in addition to the spatial consideration. Cross-continent studies, as reported in this paper, facilitate international learning on identifying effective approaches to reduce inequality.

Author Contributions: Conceptualization, M.Z. and Z.L.; methodology and data compilation, Z.L., M.Z., and L.L.; validation, Z.L., M.Z. and L.L.; formal analysis, Z.L.; resources, Z.L. and L.L.; writingoriginal draft preparation, Z.L.; writing—review and editing, Z.L. and M.Z.; visualization, Z.L.; supervision, M.Z.; project administration, M.Z.; funding acquisition, M.Z. and L.L. All authors have read and agreed to the published version of the manuscript.

Funding: This research was funded by USDOT UTC Cooperative Mobility for Competitive Megaregions Grant and The National Natural Science Youth Foundation of China (grant number 51908258).

Institutional Review Board Statement: Not applicable.

Informed Consent Statement: Not applicable.

Data Availability Statement: The datasets are available at https:/ /ec.europa.eu/eurostat/data/ database (accessed on 3 June 2021); https:/ / www.census.gov/ data.html (accessed on 3 June 2021) and http:/ / www.stats.gov.cn/tjsj/ndsj/2016/indexeh.htm (accessed on 3 June 2021).

Conflicts of Interest: The authors declare no conflict of interest when writing this paper.

\section{References}

1. Folmer, H.; Oosterhaven, J. Spatial Inequalities and Regional Development: A Framework. Spat. Inequal. Reg. Dev. 1979, 1-19. [CrossRef]

2. Kilroy, A. Intra-Urban Spatial Inequalities: Cities as 'Urban Regions.' Urban Regions 27. Available online: https: / / openknowledge.worldbank.org/handle/10986/9144 (accessed on 20 May 2021).

3. Kim, S. Spatial Inequality and Econmoic Development: Theories, Facts and Policies; World Bank: Washington, DC, USA, 2008. Available online: https://documents.worldbank.org/en/publication/documents-reports/documentdetail/8036614683309721 27/Spatial-inequality-and-economic-development-theories-facts-and-policies (accessed on 20 May 2021).

4. The Sustainable Development Goals Report; United Nations: New York, NY, USA, 2020; p. 63.

5. Dollars, D. Globalization, Inequality, and Poverty since 1980; Development Research Group, World Bank: Washington, DC, USA, 2001.

6. Kemeny, T.; Storper, M. Superstar Cities and Left-Behind Places: Disruptive Innovation, Labor Demand, and Interregional Inequality. Int. Inequal. Inst. 2020, 41, 38.

7. Wei, Y.D. Spatiality of Regional Inequality. Appl. Geogr. 2015, 61, 1-10. [CrossRef]

8. Kanbur, R.; Venables, A.J. Spatial Inequality and Development; OUP Oxford: Oxford, UK, 2005; ISBN 978-0-19-153530-7.

9. Carbonell, A.; Yaro, B. Carbonell: American Spatial Development and the New Megalopolis. Land Lines 2005, 17, 1-4. 
10. Regional Plan Association America 2050: A Prospectus. New York. 2006. Available online: https://rpa.org/work/reports/ america-2050-prospectus (accessed on 20 May 2021).

11. China Is Trying to Turn Itself intno a Country of 19 Super-Regions. The Economist, 23 June 2018. Available online: https: //www.economist.com/china/2018/06/23/china-is-trying-to-turn-itself-into-a-country-of-19-super-regions (accessed on 20 May 2021).

12. Zhou, Y.; Liu, Y.; Chen, X.; Xu, M.; Sun, S. Rising of Super City Clusters; The Boston Consulting Group: Boston, MA, USA, 2018; Volume 28. Available online: https:/ / www.bcg.com/en-us/rising-of-super-city-clusters-envision-an-urban-future-for-all (accessed on 20 May 2021).

13. Cavanaugh, A.; Breau, S. Locating Geographies of Inequality: Publication Trends across OECD Countries. Reg. Stud. 2018, 52, 1225-1236. [CrossRef]

14. ESDP-European Spatial Development Perspective: Towards Balanced and Sustainable Development of the Territory of the European Union; Office for Official Publication of the European Communities: Luxembourg, 1999; ISBN 978-92-828-7658-9.

15. China Mid/Long-Range Rail Network Plan 2016; National Development and Reform Commission: Beijing, China. 2016. Available online: https: / / www.gov.cn/xinwen/2016-07/20/5093165/files/1ebe946db2aa47248b799a1deed88144.pdf (accessed on 20 May 2021).

16. Bradley-Depani, N.; Butcher, L.; Sandford, M. The Northern Powerhouse; House of Commons Library, UK Parliament: London, UK, 2016; p. 38.

17. Dash Nelson, G.; Rae, A. An Economic Geography of the United States: From Commutes to Megaregions. PLoS ONE 2016, 11, e0166083. [CrossRef] [PubMed]

18. Florida, R.; Gulden, T.; Mellander, C. The Rise of the Mega-Region. Camb. J. Reg. Econ. Soc. 2008, 1, 459-476. [CrossRef]

19. Ross, C.L.; Woo, M. Identification and Assessment of Potential High-Speed Rail Routes from Megaregion Perspective. Transp. Res. Rec. 2012, 2307, 31-42. [CrossRef]

20. Hall, P.G.; Pain, K. The Polycentric Metropolis: Learning from Mega-City Regions in Europe; Routledge: London, UK, 2006; ISBN 978-1-84407-329-0.

21. Yin, M.; Bertolini, L.; Duan, J. The Effects of the High-Speed Railway on Urban Development: International Experience and Potential Implications for China. Prog. Plan. 2015, 98, 1-52. [CrossRef]

22. Wei, Y.D.; Li, H.; Yue, W. Urban Land Expansion and Regional Inequality in Transitional China. Landsc. Urban Plan. 2017, 163, 17-31. [CrossRef]

23. Fan, C.C.; Casetti, E. The Spatial and Temporal Dynamics of US Regional Income Inequality, 1950-1989. Ann. Reg. Sci. 1994, 28, 177-196. [CrossRef]

24. Kuznets, S. Economic Growth and Income Inequality. Am. Econ. Assoc. 1955, 45, 31.

25. Williamson, J.G. Regional Inequality and the Process of National Development: A Description of the Patterns. Econ. Dev. Cult. Chang. 1965, 13, 1-84. [CrossRef]

26. Rey, S.J.; Montouri, B.D. US Regional Income Convergence: A Spatial Econometric Perspective. Reg. Stud. 1999, 33, 143-156. [CrossRef]

27. Benner, C.; Pastor, M. Moving On Up? Regions, Megaregions, and the Changing Geography of Social Equity Organizing. Urban Aff. Rev. 2011, 47, 315-348. [CrossRef]

28. Woo, M.; Ross, C.L.; Boston, T.D. Do Megaregions Produce Greater Regional Convergence or Divergence? Implications for Spatial Planning and Infrastructure Investment. J. Urban Plann. Dev. 2015, 141, 04014013. [CrossRef]

29. Wei, Y.D. Regional Inequality in China. Prog. Hum. Geogr. 1999, 23, 49-59. [CrossRef]

30. Ureña, J.M.; Menerault, P.; Garmendia, M. The High-Speed Rail Challenge for Big Intermediate Cities: A National, Regional and Local Perspective. Cities 2009, 26, 266-279. [CrossRef]

31. Ortega, E.; López, E.; Monzón, A. Territorial Cohesion Impacts of High-Speed Rail at Different Planning Levels. J. Transp. Geogr. 2012, 24, 130-141. [CrossRef]

32. Monzón, A.; Ortega, E.; López, E. Efficiency and Spatial Equity Impacts of High-Speed Rail Extensions in Urban Areas. Cities 2013, 30, 18-30. [CrossRef]

33. Chen, C.-L.; Hall, P. The Wider Spatial-Economic Impacts of High-Speed Trains: A Comparative Case Study of Manchester and Lille Sub-Regions. J. Transp. Geogr. 2012, 24, 89-110. [CrossRef]

34. Gutikrez, J.; Gonziilez, R.; Gdmez, G. The European High-Speed Train Network. Predicted effects on accessibility patterns. J. Transp. Geogr. 1996, 4, 227e38.

35. Vickerman, R.; Spiekermann, K.; Wegener, M. Accessibility and Economic Development in Europe. Reg. Stud. 1999, 33, 1-15. [CrossRef]

36. Vickerman, R. Can High-Speed Rail Have a Transformative Effect on the Economy? Transp. Policy 2018, 62, 31-37. [CrossRef]

37. Chen, Z.; Haynes, K.E. Impact of High-Speed Rail on Regional Economic Disparity in China. J. Transp. Geogr. 2017, 65, 80-91. [CrossRef]

38. Liu, L.; Zhang, M. High-Speed Rail Impacts on Travel Times, Accessibility, and Economic Productivity: A Benchmarking Analysis in City-Cluster Regions of China. J. Transp. Geogr. 2018, 73, 25-40. [CrossRef]

39. Kim, H.; Sultana, S.; Weber, J. A Geographic Assessment of the Economic Development Impact of Korean High-Speed Rail Stations. Transp. Policy 2018, 66, 127-137. [CrossRef] 
40. Jiao, J.; Wang, J.; Jin, F.; Dunford, M. Impacts on Accessibility of China's Present and Future HSR Network. J. Transp. Geogr. 2014, 40, 123-132. [CrossRef]

41. Zhu, P.; Yu, T.; Chen, Z. High-Speed Rail and Urban Decentralization in China. Transp. Res. Rec. 2015, 2475, 16-26. [CrossRef]

42. Chen, C.-L.; Vickerman, R. Can Transport Infrastructure Change Regions' Economic Fortunes? Some Evidence from Europe and China. Reg. Stud. 2017, 51, 144-160. [CrossRef]

43. Statistics I Eurostat. Available online: https://ec.europa.eu/eurostat/databrowser/view/demo_r_pjanind3/default/table?lang= en (accessed on 23 May 2021).

44. U.S. Census Bureau. Business Dynamics Statistics Datasets. Available online: https:/ /www.census.gov/data/datasets/timeseries/econ/bds/bds-datasets.html (accessed on 23 May 2021).

45. BEA: Regional Economic Accounts: Download. Available online: https://apps.bea.gov/ (accessed on 24 May 2021).

46. China Statistical Yearbook-2016. Available online: http://www.stats.gov.cn/tjsj/ndsj/2016/indexeh.htm (accessed on 31 May 2021).

47. Jayet, H. Analyse Spatiale Quantitative: Une Introduction; Economica: Paris, France, 1993; ISBN 978-2-7178-2492-6.

48. World Bank. Regional Economic Impact Analysis of High Speed Rail in China: Main Report; World Bank: Washington, DC, USA, 2014. Available online: https:/ / openknowledge.worldbank.org/handle/10986/2204 (accessed on 4 June 2021).

49. Zheng, S.; Kahn, M.E. China's Bullet Trains Facilitate Market Integration and Mitigate the Cost of Megacity Growth. Proc. Natl. Acad. Sci. USA 2013, 110, E1248-E1253. [CrossRef]

50. Rey, S.J.; Janikas, M.V. Regional Convergence, Inequality, and Space. J. Econ. Geogr. 2005, 5, 155-176. [CrossRef]

51. Lessmann, C.; Seidel, A. Regional Inequality, Convergence, and Its Determinants-A View from Outer Space. Eur. Econ. Rev. 2017, 92, 110-132. [CrossRef]

52. Atkinson, R.D.; Muro, M.; Whiton, J. The Case for Growth Centers: How to Spread Tech Innovation across America; Brookings: Washington, DC, USA, 2019. Available online: https://www.brookings.edu/research/growth-centers-how-to-spread-techinnovation-across-america/ (accessed on 20 May 2021).

53. Rosés, J.R.; Sanchis, M.T. A long-run perspective on French regional income inequality, 1860-2010. In The Economic Development of Europe's Regions; Routledge: London, UK, 2018; ISBN 978-0-429-44978-9.

54. McAvay, H.; Verdugo, G. Income Inequality and Segregation in the Paris Metro Area (1990-2015). In Urban Socio-Economic Segregation and Income Inequality; Springer: Cham, Switzerland, 2021; pp. 329-345, Open Access. Available online: https://www. researchgate.net/publication/350463067_Income_Inequality_and_Segregation_in_the_Paris_Metro_Area_1990-2015 (accessed on 20 May 2021). 